\title{
Radial artery reliability using arterial Doppler assessment prior to arterial cannulation
}

\author{
Evan Roter, MD, FRCPC • André Y. Denault, MD, PhD, FRCPC, ABIM-CCM, FASE, FCCS $₫$
}

Received: 18 June 2019/Revised: 21 June 2019/Accepted: 22 June 2019/Published online: 9 July 2019

(c) Canadian Anesthesiologists' Society 2019

\section{To the Editor,}

Use of invasive blood pressure monitoring is an integral aspect of management in both operative and critically ill patients. It allows for beat-to-beat measurement of blood pressure and can be utilized to measure dynamic variables such as pulse pressure variation. ${ }^{1}$ Fortunately, the radial artery is usually an easily accessible and dependable site for direct cannulation for invasive blood pressure monitoring. Nevertheless, to reliably interpret the blood pressure data from it, one must ensure the integrity of the pressure monitoring system components, and assume that no obstructions at the level of the catheter or the proximal vasculature exist.

Herein we report a 69-yr-old female admitted to our cardiac surgical intensive care unit following coronary artery bypass grafting. She had known coronary artery disease, hypertension, and dyslipidemia. Preoperatively, the patient underwent an upper extremity vascular investigation prompted by reported paresthesia and weakness in the left arm. Doppler exam revealed a hemodynamically significant lesion with a pressure gradient calculated at $50 \mathrm{mmHg}$ and a permanent left vertebral artery steal. On computed tomography angiogram, a plaque was noted $3.5 \mathrm{~cm}$ from the origin of the left subclavian artery, upstream from the left vertebral

E. Roter, MD, FRCPC

Department of Anesthesiology, McGill University, Montreal, QC, Canada

A. Y. Denault, MD, PhD, FRCPC, ABIM-CCM, FASE, FCCS $(\bowtie)$

Department of Anesthesiology, and Cardiac Surgical Intensive Care Division, Montreal Heart Institute, Université de Montréal, Montreal, QC, Canada

e-mail: andre.denault@umontreal.ca artery. The caliber of the vessel diminished from $6.5 \mathrm{~mm}$, proximal to the stenosis, to a minimum of $2 \mathrm{~mm}$, with an estimated stenosis of $70 \%$. With this information, a right radial cannula was utilized intraoperatively. Without this information, management of vasoactive medications and fluids could have been guided by inaccurate measurements and could have resulted in significant morbidity. Nevertheless, in the absence of symptoms and formal investigations such as above, there is a way at the bedside to rule out any proximal stenosis and be confident that the arterial cannula is representative of systemic pressures.

Bilateral non-invasive blood pressure measurements is one screening test for subclavian stenosis. In a study of 1,248 patients, subclavian stenosis was present in $7 \%$ of the population. ${ }^{2}$ Nevertheless, non-invasive blood pressure may not be sensitive enough to detect a stenosis with the potential to become hemodynamically significant secondary to alterations in vascular resistance with surgery, anesthesia, or the use of vasopressors. ${ }^{3}$ Among the various modalities utilized for vascular assessment, Doppler ultrasound examination is a rapid, easy, and reliable technique that can be utilized prior to cannulation of any artery.

With the patient's consent, we performed a bedside vascular Doppler examination of the upper limbs postoperatively (Figure). Although numerous locations and measurements must be investigated during a complete Doppler examination, there are some easily identifiable features used to assess a hemodynamically significant proximal obstruction. Normally, in the highresistance vessels of the extremities, a triphasic pattern is obtained. This pattern along with normal peak systolic velocities excludes any significant obstruction. ${ }^{4}$ Loss of the diastolic flow reversal is definite evidence of a significant proximal lesion, ${ }^{4}$ and the presence of a tardus parvus 


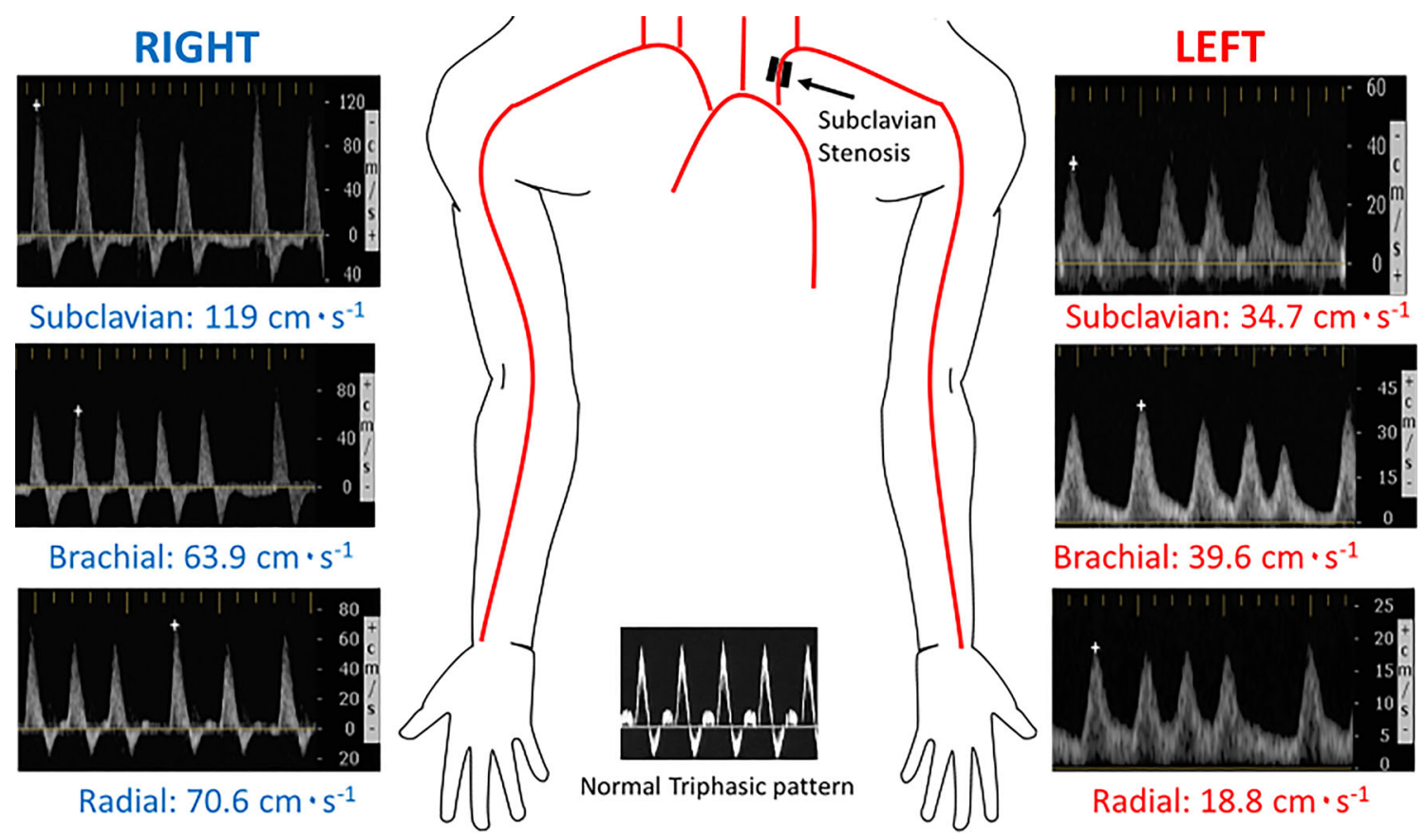

Figure Bilateral upper extremity Doppler assessment of the subclavian, brachial, and radial arteries in a 69-yr-old female with left arm paresthesia and weakness. On the right limb (blue) we found a normal triphasic waveform, with a brisk systolic upstroke reaching peak systolic velocities within the normal range (subclavian artery 70-

waveform is very specific but less sensitive evidence for an obstruction. Finally, continuous diastolic flow velocity should not be present in muscular arterial Doppler signals. ${ }^{5}$ Excellent reviews and an online video (https://www. youtube.com/watch?v=4JyRA2xSQ6o) on arterial Doppler waveform analysis can be consulted for further information. $^{5}$

We recognize that performing a vascular study prior to all arterial cannulae insertions may not be feasible or indicated, and that some of the knowledge and skills required for an accurate interpretation of the findings may be well beyond the scope of practice of those inserting arterial cannulae. Nevertheless, when risk factors such as a smoking history, hypertension, dyslipidemia, and peripheral arterial disease are present, a Doppler assessment on bilateral radial arteries may serve as an effective screening tool to avoid use of an entirely inaccurate pressure reading.

Funding No funding was required.

Conflicts of interest The authors have no conflicts of interest to declare.
$120 \mathrm{~cm} \cdot \mathrm{sec}^{-1}$; brachial artery $50-100 \mathrm{~cm} \cdot \mathrm{sec}^{-1}$; radial artery $40-90$ $\left.\mathrm{cm} \cdot \mathrm{sec}^{-1}\right) .{ }^{5}$ On the left limb (red), we see various signs representative of significant proximal obstruction: loss of the triphasic waveform, delayed arrival of the systolic peak (pulsus tardus), and diminished peak systolic velocities (pulsus parvus) and diastolic flow.

Editorial responsibility This submission was handled by Dr. Hilary P. Grocott, Editor-in-Chief, Canadian Journal of Anesthesia.

\section{References}

1. Yazigi A, Khoury E, Hlais $S$, et al. Pulse pressure variation predicts fluid responsiveness in elderly patients after coronary artery bypass graft surgery. J Cardiothorac Vasc Anesth 2012; 26: 387-90.

2. Shadman R, Criqui MH, Bundens WP, et al. Subclavian artery stenosis: prevalence, risk factors, and association with cardiovascular diseases. J Am Coll Cardiol 2004; 44: 618-23.

3. Currigan DA, Hughes RJ, Wright CE, Angus JA, Soeding PF. Vasoconstrictor responses to vasopressor agents in human pulmonary and radial arteries: an in vitro study. Anesthesiology 2014; 121: 930-6.

4. Taneja K, Jain R, Sawhney S, Rajani M. Occlusive arterial disease of the upper extremity: colour Doppler as a screening technique and for assessment of distal circulation. Australas Radiol 1996; 40: 226-9.

5. Pellerito J, Polak J. Introduction to Vascular Ultrasonography. 6th ed. London, United Kingdom: Elsevier Health Sciences; 2012 .

Publisher's Note Springer Nature remains neutral with regard to jurisdictional claims in published maps and institutional affiliations. 